\title{
OPTIMUM PASSIVE TUNED MASS DAMPER SYSTEMS FOR MAIN STRUCTURES UNDER HARMONIC EXCITATION
}

\author{
Onur ARAZ \\ Gümüşhane University, Faculty of Engineering and Natural Sciences, Department of Civil Engineering, \\ Gümüşhane, Turkey
}

\begin{tabular}{ll}
\hline Keywords & Abstract \\
\hline Tuned Mass Damper, & To increase the effectiveness and robustness of a single Tuned mass damper (TMD), \\
Dynamic Response, & TMDs are connected in series or parallel to the main system. Unlike parallel TMDs \\
Optimization, & (PTMD), series TMDs (STMD) consist of only two different TMD units, each of which \\
Optimum Parameter, & is connected to the main structure in series. The optimum parameters of series and \\
Simulated Annealing. & $\begin{array}{l}\text { parallel TMDs are obtained by using the simulated annealing (SA) algorithm in this } \\
\text { study. It is aimed to minimize the displacement in the main system in obtaining the } \\
\text { optimum parameters. Also, the explicit formulas that can be easily used for the } \\
\text { optimum design of both TMD devices are derived using the curve-fitting technique. } \\
\text { The control performance of the optimum STMD device is confirmed through } \\
\text { numerical analyses and compared with classical TMD and PTMD. }\end{array}$ \\
\end{tabular}

\section{HARMONIK ETKİ ALTINDAKİ ANA YAPILAR İÇİN OPTIMUUM PASİF AYARLI KÜTLE SÖNÜMLEYİCI SİSTEMLER}

\begin{tabular}{ll}
\hline Anahtar Kelimeler & Öz \\
\hline Ayarlı Kütle Sönümleyici, & Tek bir ayarlı kütle sönümleyicinin (AKS) etkinliğini ve sağlamlığını artırmak için, \\
Dinamik Davranış, & AKS'ler ana sisteme paralel ya da seri olarak bağlanırlar. Paralel bağlı AKS'lerden \\
Optimizasyon, & farklı olarak seri bağlı AKS’ler ana sisteme seri olarak bağlı iki farklı AKS'den \\
Optimum Parametre, & meydana gelmektedir. Bu çalışmada seri ve paralel bağlı AKS'lerin optimum \\
Benzetilmiş Tavlama. & parametreleri benzetilmiş tavlama algoritması kullanılarak elde edilmiştir. \\
& Optimum parametrelerin elde edilmesinde ana sistemdeki yer değiştirmenin en aza \\
& indirilmesi amaçlanmıștır. Ayrıca, her iki AKS cihazının optimum tasarımı için \\
& kolayca kullanılabilen açı formüller, eğri uydurma tekniği kullanılarak \\
& türetilmiştir. Optimum seri bağlı AKS sisteminin kontrol performansı sayısal \\
& analizlerle doğrulanmış ve klasik AKS ve paralel bağlı AKS ile karşıllaştırılmıştır. \\
\hline
\end{tabular}

Alıntı / Cite

Araz, O., (2021). Optimum Passive Tuned Mass Damper Systems For Main Structures Under Harmonic Excitation, Journal of Engineering Sciences and Design, 9(4), 1062-1071.

\begin{tabular}{|l|l}
\hline Yazar Kimliği / Author ID (ORCID Number) & Makale Süreci / Article Process
\end{tabular}

\begin{tabular}{l|l}
\hline O. Araz, 0000-0002-6218-0559 & Başvuru Tarihi / Submission Date
\end{tabular}

Revizyon Tarihi / Revision Date

Kabul Tarihi / Accepted Date

Yayım Tarihi / Published Date $\quad 20.12 .2021$

\section{Introduction}

TMDs are very effective in mitigating the dynamic vibrations of the structures and it is a device consisting of a spring, a damper and a mass. The TMDs are usually tuned to the dominant frequency of the structure. Because of mechanical simplicity, small requirements and low cost for maintenance, TMD is commonly used in various reallife structures.

The TMD systems have often been applied for suppressing the vibrations induced on real structures under undesirable excitations. Historically, many investigators have contributed to the improvement of TMD systems.

\footnotetext{
* ilgili yazar / Corresponding author: onuraraz29@hotmail.com, +90-456-233-1645
} 
Den Hartog (1956) proposed a closed form solution to minimize the vibrations of undamped primary structure under harmonic loads and also obtained optimum parameters for TMD. Later, numerous investigators have investigated the optimum design of the TMD under different external excitations (Fujino and Abe, 1993, Rana and Soong, 1998, Leung et al., 2008, Matta, 2013, Salvi and Rizzi, 2016, Cetin et al., 2017, Bekdaş et al., 2018, Cetin et al., 2019, Aydin et al., 2020).

The studies mentioned above are concerned with tuning TMD to a dominant frequency of the main system. However, single TMD is very sensitive to any deviation in the frequency of TMD and/or the main system. Errors in identifying the main system frequency or in manufacturing TMD lead to the detuning effect. To overcome the detuning due to a frequency deviation in the main system or TMD, Xu and Igusa (1992) proposed to use parallel TMDs (PTMD) instead of classic single TMD. The optimal parameters of PTMD system have received considerable attention from researchers since the invention of this device because of its significant number of dynamic parameters. Thus, many studies on the design method and control effectiveness have been theoretically performed (Bakre and Jangid, 2004, Li and Ni, 2007, Mohebbi et al., 2015, Kim and Lee, 2018). These studies show that optimally designed PTMD is more effective and robust than a single TMD in reducing structural vibrations.

Most of the previous research on TMD devices are concerned with obtaining optimum parameters of single TMD and PTMD and their control effectiveness. Only a few researchers have investigated the practical applications of STMD for an undamped structure due to various external excitations. Li and Zhu (2006) studied the performance of STMD system attached to an undamped main system excited by ground acceleration. Then, the performance of STMD system is investigated on an undamped main structure excited by harmonic base excitations (Zuo, 2009, Asami, 2018, Asami et al., 2018).

The above-mentioned works related to the STMD mostly adopt its optimal design and effectiveness for an undamped system under different external excitations. According to the best of the authors' knowledge, the damped main system under harmonic excitation equipped with STMD system have not yet been studied. In addition, a comparative study on control performances of the passive control devices (i.e., TMD, PTMD and STMD) under errors in the structural parameter with different mass ratios has not been performed yet. The above state of the art leads to the motivation for further investigation of the TMD systems in this work. The main objectives of this paper are: (i) to determine the optimum parameters of both STMD and PTMD devices with the SA method, (ii) to derive explicit expressions using a curve- fitting scheme for practical applications of both STMD and PTMD devices, (iii) to compare the control performance and optimal parameters of the STMD and PTMD with respect to that of the classical TMD, and (iv) to study the detuning effect on their control effectiveness.

\section{Structural Model}

Figs. 1 (a) and (b) describe a PTMD and an STMD attached to main system, respectively. When the number of TMD units in the PTMD and STMD systems is equal to one, these devices denote the classical TMD. $m_{s}, c_{s}$ and $k_{s}$ indicate the mass, damping constant and stiffness of the main system, respectively. The natural frequency and viscous damping ratio of the main structure denote $\omega_{s}$ and $\xi_{s}$, respectively. $m_{j}, c_{j}$ and $k_{j}$ are the mass, damping and stiffness of the $j$ th TMD. And, $\omega_{j}$ and $\xi_{j}$ are the natural frequency and damping ratio of the TMD, respectively. The total degrees of freedom of the main system with TMDs is 3.

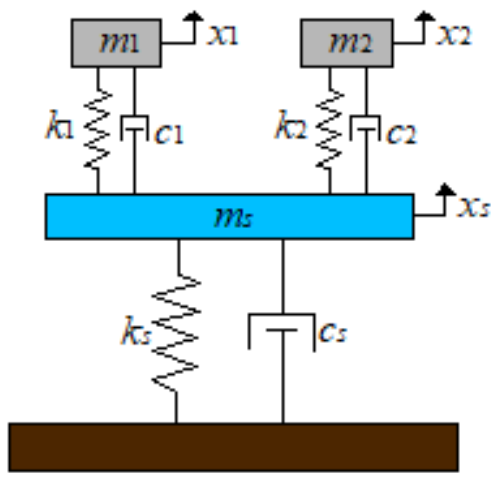

(a)

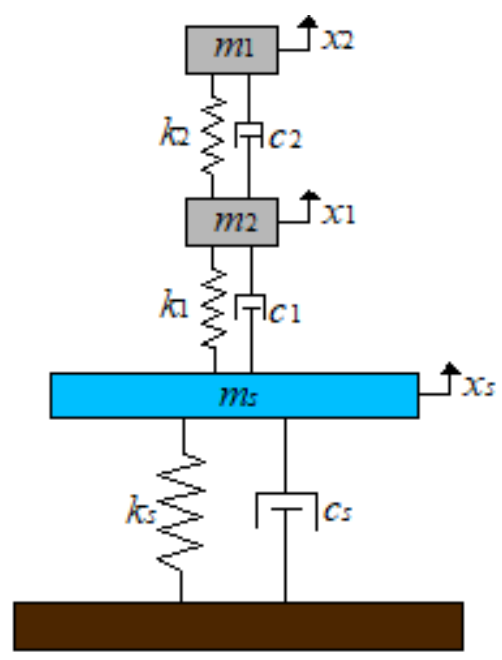

(b)

Figure 1. Structural system for (a) PTMD and (b)STMD devices, respectively 
The equations of motion for a main system equipped with TMD devices shown in Fig. 1 can be expressed in a matrix form as

$$
M \ddot{Y}+C \dot{Y}+K Y=F
$$

$M, C, K$ represent the mass, damping and stiffness matrices in the equation while stmd and ptmd subscripts represent the STMD and PTMD systems, respectively. F represents the external force vector.

$$
\begin{gathered}
M_{p t m d}=M_{s t m d}=\left[\begin{array}{ccc}
m_{s} & 0 & 0 \\
0 & m_{1} & 0 \\
0 & 0 & m_{2}
\end{array}\right] \\
C_{p t m d}=\left[\begin{array}{ccc}
c_{s}+\sum c_{i} & -c_{1} & -c_{2} \\
-c_{1} & c_{1} & 0 \\
-c_{2} & 0 & c_{2}
\end{array}\right], C_{s t m d}=\left[\begin{array}{ccc}
c_{s}+c_{1} & -c_{1} & 0 \\
-c_{1} & c_{1}+c_{2} & -c_{2} \\
0 & -c_{2} & c_{2}
\end{array}\right] \\
K_{p t m d}=\left[\begin{array}{ccc}
k_{s}+\sum k_{i} & -k_{1} & -k_{2} \\
-k_{1} & k_{1} & 0 \\
-k_{2} & 0 & k_{2}
\end{array}\right], K_{s t m d}=\left[\begin{array}{ccc}
k_{s}+k_{1} & -k_{1} & 0 \\
-k_{1} & k_{1}+k_{2} & -k_{2} \\
0 & -k_{2} & k_{2}
\end{array}\right] \\
Y_{p t m d}=Y_{s t m d}=\left[\begin{array}{l}
x_{s} \\
x_{1} \\
x_{2}
\end{array}\right] \\
F_{p t m d}=F_{s t m d}=\{f(t) \\
0
\end{gathered}
$$

where the external excitation force acting on the sdof structure is modeled by harmonic force expressed by

$$
f(t)=f_{o} e^{i \omega t}
$$

Here, $f_{o}, \omega$ and $t$ are the amplitude, circular frequency and time, respectively. The steady-state structural response under the harmonic excitation is expressed as

$$
Y(\omega)=\left(-\omega^{2}[M]+i \omega[C]+[K]\right)^{-1} f_{o}
$$

Finally, the dynamic magnification factor (DMF) of the main structure is formulated as follows:

$$
D M F=\frac{|Y(\omega)|}{f_{o} / k_{s}}
$$

\section{Optimization Procedure}

General formulation of unconstrained optimization problems can be expresses as follow

$$
\min J(q) \quad \text { with } q^{L} \leq q \leq q^{U}
$$

where $q$ is termed as the design vector, which is defined as $p$-dimensional vector and $J(q)$ denotes the objective function. $q^{U}$ and $q^{L}$ are the upper and lower bound vectors of the design variables, respectively.

The optimum parameters of the TMD are obtained by the Simulated Annealing (SA) method. Kirkpatrick et al. (1983) are the first to introduce the SA method, which has become a more popular method in solving optimization problems in the past several decades. The slow cooling of the molten metal is simulated by the SA meth od to obtain the minimum function value. By adding a temperature-like parameter is simulated the cooling phenomenon of the molten metal is simulated and the concept of Boltzmann's probability distribution is used to control the system. The flowchart of SA is given in Fig. 2.

The mass ratio $\mu$ of the TMD system and damping ratio $\xi_{s}$ of the main system are initially known. Therefore, there are two variables of optimization (i.e. $\xi_{1}$ and $f_{1}$ ) for the classical TMD; $\xi_{T}, \beta$ and $f_{T}$ are the three variables for the optimization of the PTMD; $\xi_{1}, \xi_{2}, f_{1}, f_{2}$ and $\mu_{H}$ are the five variables for the optimization of the STMD. 


$$
\begin{aligned}
& \mu=\frac{m_{T}}{m_{s}}, \quad \xi_{i}=\frac{c_{i}}{2 m_{i} \omega_{i}}, \quad f_{i}=\frac{\omega_{i}}{\omega_{s}}, \quad i=1,2 \\
& \mu_{H}=\frac{m_{1}}{m_{2}}, \quad f_{T}=\frac{\omega_{T}}{\omega_{s}}, \quad \beta=\frac{\omega_{2}-\omega_{1}}{\omega_{T}}
\end{aligned}
$$

where $\xi_{i}$ and $f_{i}$ are the damping ratio and frequency ratio of $i$ th control device, respectively; $\mu$ is the total mass ratio; $\mu_{H}$ is the mass ratio of the smaller TMD to the larger one in STMD; $m_{T}$ is the total mass of TMD units; $\omega_{T}, \beta$ and $f_{T}$ represent the average frequency, frequency band-width and tuning frequency ratio of the PTMD, respectively.

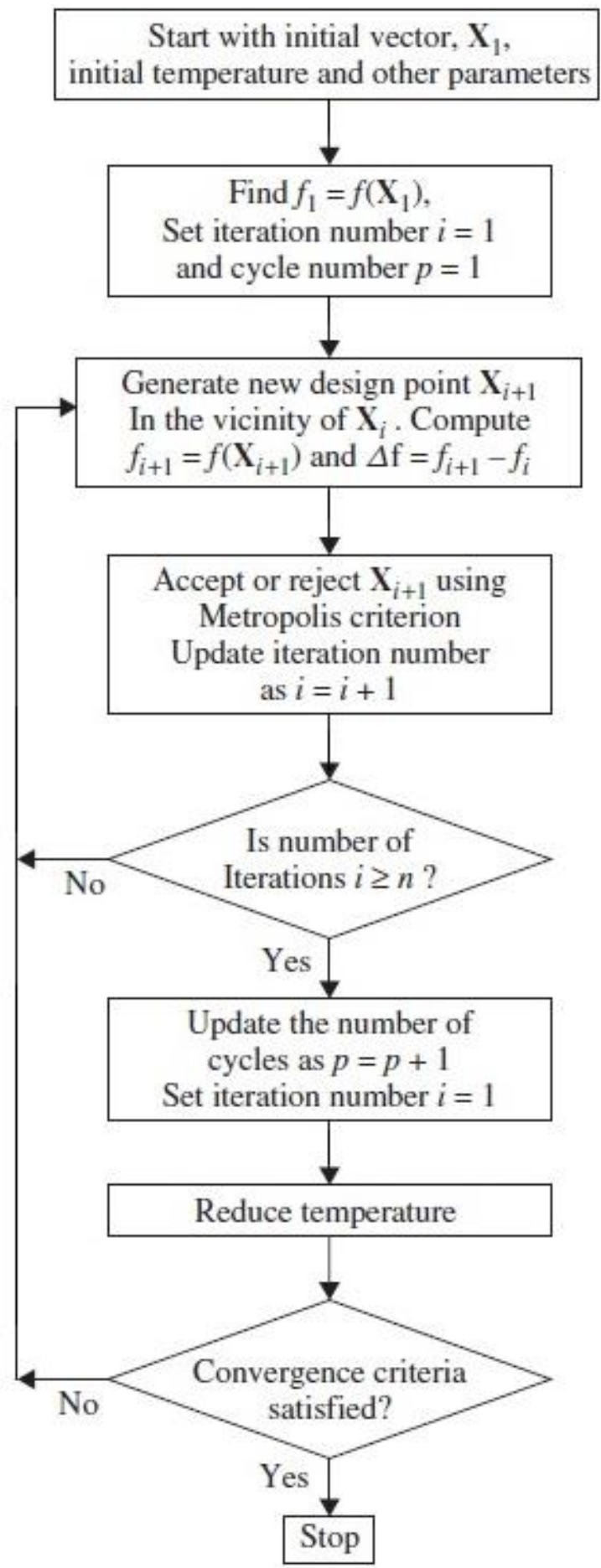

Figure 2. The flowchart of SA.

For TMD, PTMD and STMD, the following ranges are considered for the optimum design with the search increment of the variables set to be $10^{-6}$, respectively 


$$
\begin{gathered}
0 \leq \xi_{1} \leq 0.5 ; \quad 0.8 \leq f_{1} \leq 1.2 \\
0 \leq \xi_{T} \leq 0.5 ; \quad 0.8 \leq f_{T} \leq 1.2 ; \quad 0 \leq \beta \leq 0.5 \\
0 \leq \xi_{1} \leq 0.5 ; \quad 0 \leq \xi_{2} \leq 0.5 ; \quad 0.8 \leq f_{1} \leq 1.2 \\
0.8 \leq f_{2} \leq 1.2 ; \quad 10^{-5} \leq \mu_{H} \leq 1
\end{gathered}
$$

The natural frequency of the $j$ th TMD in PTMD system is formulated as

$$
\begin{gathered}
\omega_{j}=\sqrt{k_{j} / m_{j}}=\omega_{T}\left[1+\left(j-\frac{n+1}{2}\right) \frac{\beta}{n-1}\right] \\
\omega_{T}=\sum_{j=1}^{n} \frac{\omega_{j}}{n} ; \quad \beta=\frac{\omega_{n}-\omega_{1}}{\omega_{T}}
\end{gathered}
$$

where $\beta$ and $\omega_{T}$ are the frequency band-width and average frequency of the PTMD system, respectively. Also, $n$ is the total number of TMDs in PTMD system. Here, each TMD in PTMD system is designed with identical damping ratio (i.e., $\xi_{1}=\xi_{2}=\xi_{T}$ ).

\section{Optimum Parameters of TMDs}

By using SA optimization method, the optimal design parameters for various types of TMDs under the effect of external harmonic excitation are investigated in this section. These devices are a classical TMD, PTMD and STMD.

Den Hartog [2] developed closed-form expressions for the optimum parameters of TMD to reduce the steady-state response of an undamped main structure subjected to harmonic excitation. These expressions are given in Eq. (17). The results obtained by the proposed methodology are compared with results obtained through traditional TMD design methods in Fig. 3. As can be seen, the results obtained by both methods are very similar.

$$
f=\frac{1}{1+\mu} ; \quad \xi=\sqrt{\frac{3 \mu}{8(1+\mu)}}
$$
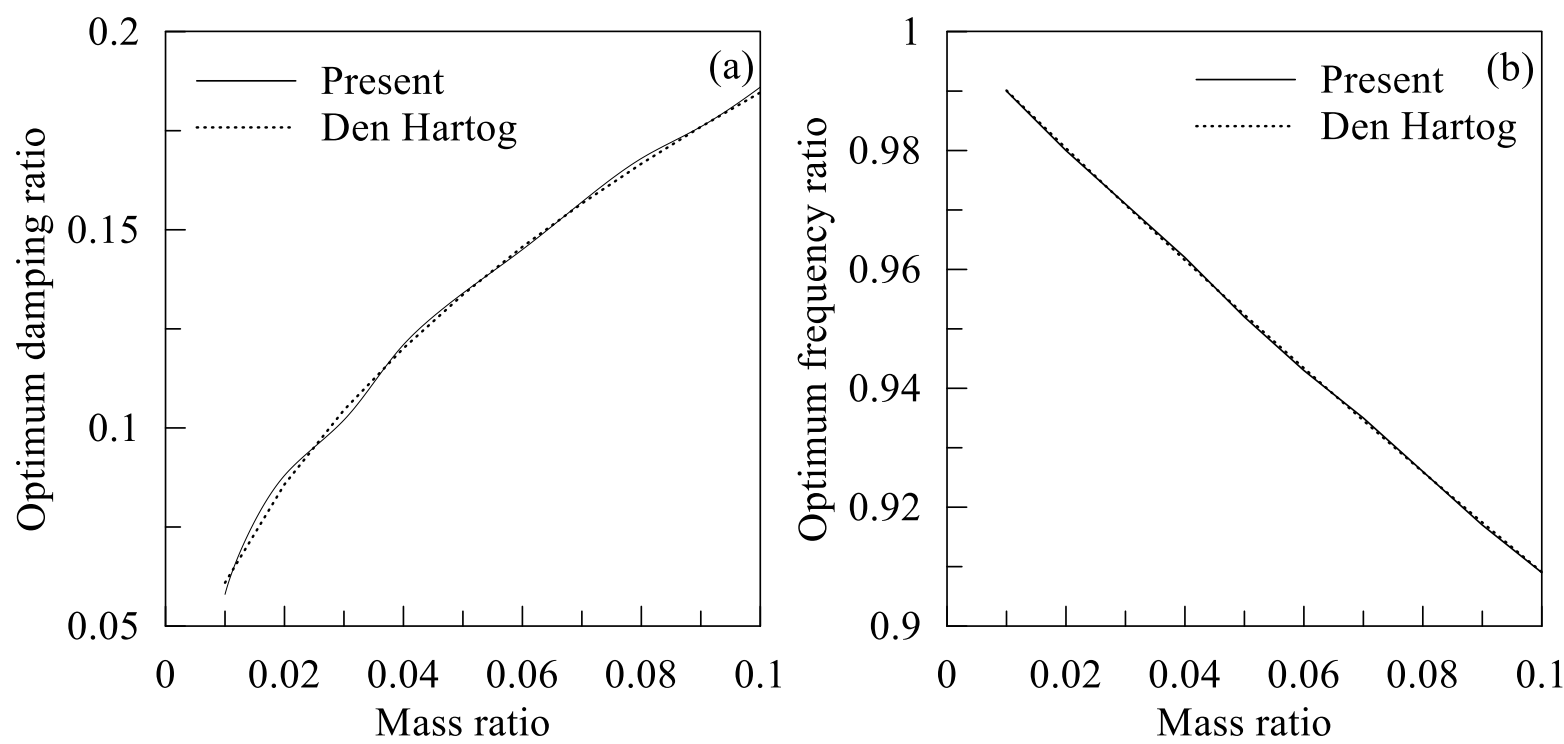

Figure 3. The optimum values obtained by both methods

Fig. 4 displays the relation curves between the optimum frequency ratio of 1st TMD in multiple TMDs and the mass ratio for $\xi_{s}=0 \%$ and $\xi_{s}=5 \% . \xi_{s}=0 \%$ and $\xi_{s}=5 \%$ are denoted by markers 'o' and ' $\Delta$ ', respectively. As a comparison, the optimum frequency ratio curves for single TMD are also plotted. As can be seen, the largest and smallest optimum frequency ratios are obtained for the STMD and PTMD systems, respectively. Fig. 4 also indicates that as the mass ratio decreases, the optimum frequency ratio of TMD and PTMD increases, whereas the optimum frequency ratio of STMD decreases. Further, the optimum frequency ratios increase with the decrease of the damping ratio of the main structure. 
Fig. 5 depicts the relation curves between the optimum frequency ratio of 2 nd TMD in multiple TMDs and the mass ratio for $\xi_{s}=0 \%$ and $\xi_{s}=5 \%$. As it can be seen, the largest and smallest optimum frequency ratios are obtained for the PTMD and STMD systems, respectively. It can also be seen from Figure 5 that with increasing mass ratio, the optimum frequency ratio of STMD and TMD decreases yet the optimum frequency ratio of PTMD is distributed close to 1.0 , that is its frequency is set close to the structural natural frequency. Moreover, as the damping ratio of the main structure decreases the optimal frequency ratios increase.

Fig. 6 displays the variation of the optimum damping ratio of 1st TMD in both TMD devices with regard to the mass ratio for $\xi_{s}=0 \%$ and $\xi_{s}=5 \%$. As a comparison, the damping ratios of the classical TMD are also plotted. As it can be seen, the optimum damping ratio of the PTMD is smaller than those of the classical TMD. It has to be also that the damping ratio of the STMD for all mass ratios are zero. Furthermore, the optimal damping ratios increase as the damping ratio of the main structure and mass ratio increase.

Fig. 7 shows the variation of the optimum damping ratio of 2 nd TMD in both TMD device with regard to the mass ratio for $\xi_{s}=0 \%$ and $\xi_{s}=5 \%$. It is noted from Fig. 7 that the largest and smallest optimum damping ratios are obtained for the STMD and PTMD systems, respectively. Further, as the structural damping ratio and mass ratio increase, the optimal damping ratios increase.

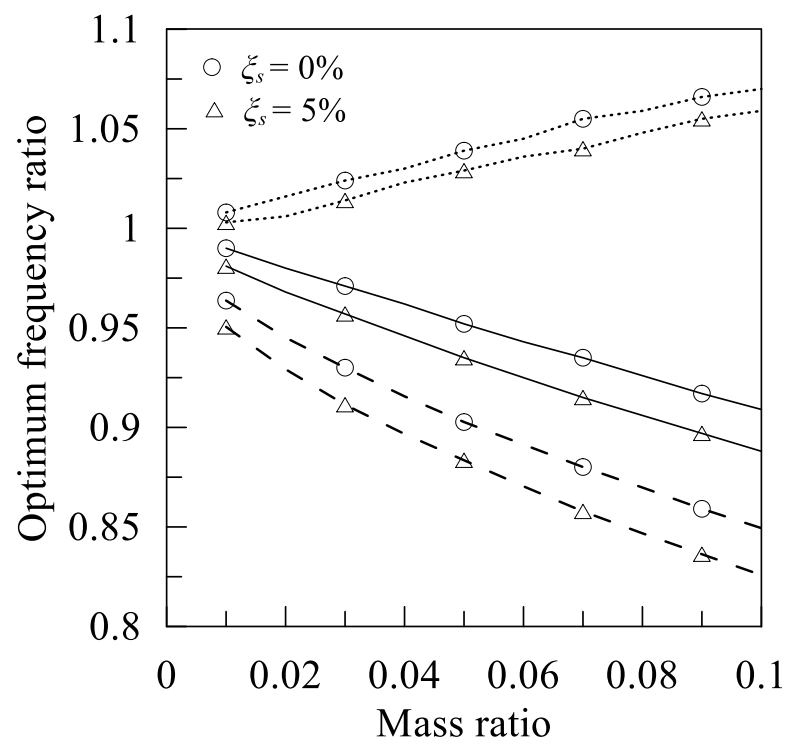

Figure 4. The relationship between the optimum frequency ratio of 1st TMD in multiple TMDs and the mass ratio (- TMD, - - - PTMD STMD)

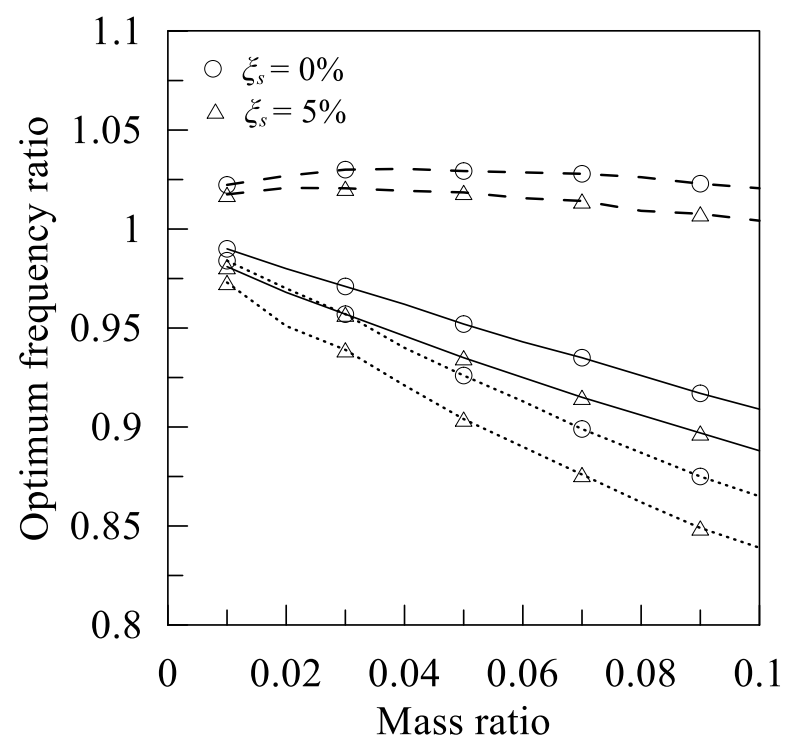

Figure 5. The relationship between the optimum frequency ratio of 2 nd TMD in multiple TMDs and the mass ratio (-— TMD, - - - PTMD, STMD) 


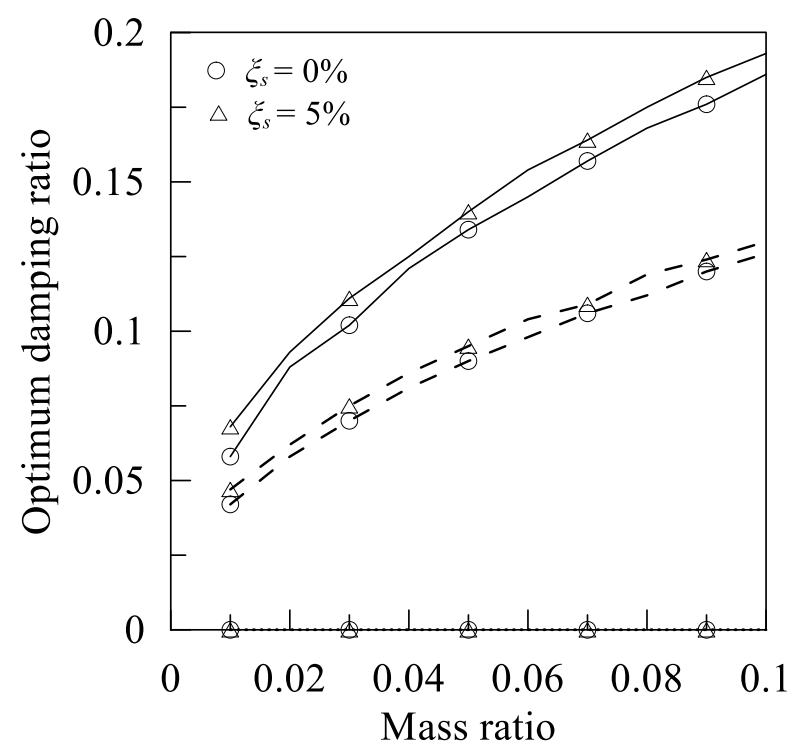

Figure 6. The relationship between the optimum damping ratio of 1st TMD in multiple TMDs and the mass ratio (-— TMD, - - - PTMD, ........... STMD)

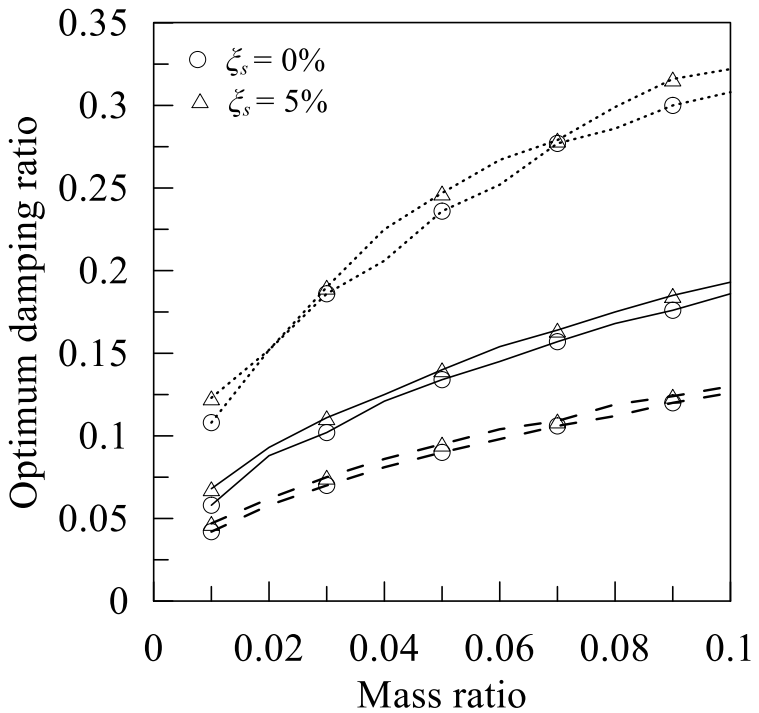

Figure 7. The relationship between the optimum damping ratio of 2nd TMD in multiple TMDs and the mass ratio (- TMD, - - - PTMD, ........... STMD)

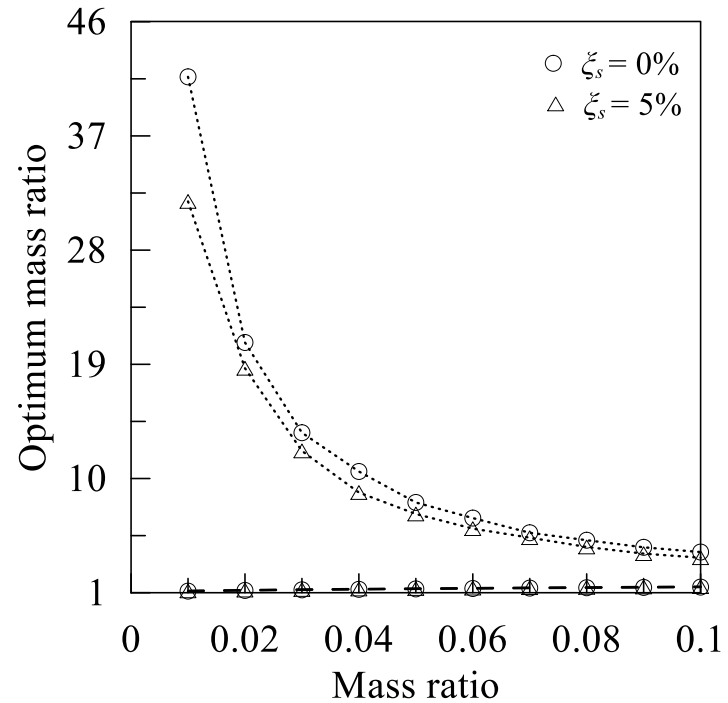

Figure 8. The relationship between the optimum mass ratio in multiple TMDs and the mass ratio (--- PTMD STMD) 
The relationship curves between the optimum mass ratios of the two types of TMDs and the mass ratio are given in Fig. 8. Fig. 8 indicates that the optimum mass ratio of STMD increases with the decrease of the structural damping ratio and the mass ratio $\mu$. Also, it should be noted that the optimum mass ratio of PTMD is obtained close to 1.0 , which means the mass of 1 st TMD unit is obtained near to the mass of 2 nd TMD unit.

The explicit formulas for the optimum design of three types of TMDs are given in Tables 1-3. Numbers in parenthesis are for R-square $\left(R^{2}\right)$ in Tables 1-3. Since these formulas are obtained in a very simple form, they can easily be used for optimum design of the TMDs. When an explicit expression is obtained by using a curve-fitting technique, its accuracy may be assessed by the R-square correlation between optimal and fitting values. If the Rsquare index gets closer to 1 , a better fitting estimate is considered. Thus, the difference between optimal and fitting values is very small in this study. The maximum difference for any value of damping ratio and frequency ratio is observed to be 1.86 and $0.11 \%$, respectively.

Table 1. Design formulas of the TMD system

\begin{tabular}{|c|c|c|}
\hline$\xi_{s}$ & $f_{1}$ & $\xi_{1}$ \\
\hline $0 \%$ & $0.9989 e^{-0.949 \mu}(0.9998)$ & $0.5882 \mu^{0.4964}(0.9972)$ \\
\hline $5 \%$ & $0.9894 e^{-1.099 \mu}(0.9983)$ & $0.5509 \mu^{0.4556}(0.9995)$ \\
\hline
\end{tabular}

Table 2. Design formulas of the PTMD system

\begin{tabular}{|c|c|c|c|}
\hline$\xi_{s}$ & $f_{T}$ & $\xi_{T}$ & $\beta$ \\
\hline $0 \%$ & $0.9994 e^{-0.667 \mu}(0.9997)$ & $0.3768 \mu^{0.4778}(0.9998)$ & $0.5723 \mu^{0.4927}(0.9999)$ \\
\hline $5 \%$ & $0.9903 e^{-0.803 \mu}(0.9985)$ & $0.3639 \mu^{0.448}(0.9989)$ & $0.5572 \mu^{0.4560}(0.9998)$ \\
\hline
\end{tabular}

Table 3. Design formulas of the STMD system

\begin{tabular}{|c|c|c|c|c|}
\hline$\xi_{s}$ & $i$ & $f_{i}$ & $\xi_{i}$ & $\mu_{H}$ \\
\hline $0 \%$ & 1 & $1.0029 e^{0.6783 \mu}(0.9933)$ & 0 (none) & \multirow{2}{*}{$0.4074 \mu^{-1.004}(0.9996)$} \\
\hline & 2 & $0.9978 e^{-1.46 \mu}(0.9985)$ & $0.9185 \mu^{0.4608}(0.9970)$ & \\
\hline $5 \%$ & 1 & $0.9959 e^{0.6321 \mu}(0.9943)$ & 0 (none) & \multirow{2}{*}{$0.4192 \mu^{-0.952}(0.9977)$} \\
\hline & 2 & $0.9848 e^{-1.649 \mu}(0.9969)$ & $0.9072 \mu^{0.4410}(0.9926)$ & \\
\hline
\end{tabular}

\section{Comparison of Control Performances}

In this section, the control performance of three systems available in suppressing the structural dynamic response is compared. The comparison is made based on DMF values.

In Fig. 9, the response DMF is plotted for both undamped $\left(\xi_{s}=0 \%\right)$ and damped $\left(\xi_{s}=5 \%\right)$ main systems, respectively. It is seen in these figures that the effectiveness of STMD system is the best, while PTMD system is better than a single TMD system.

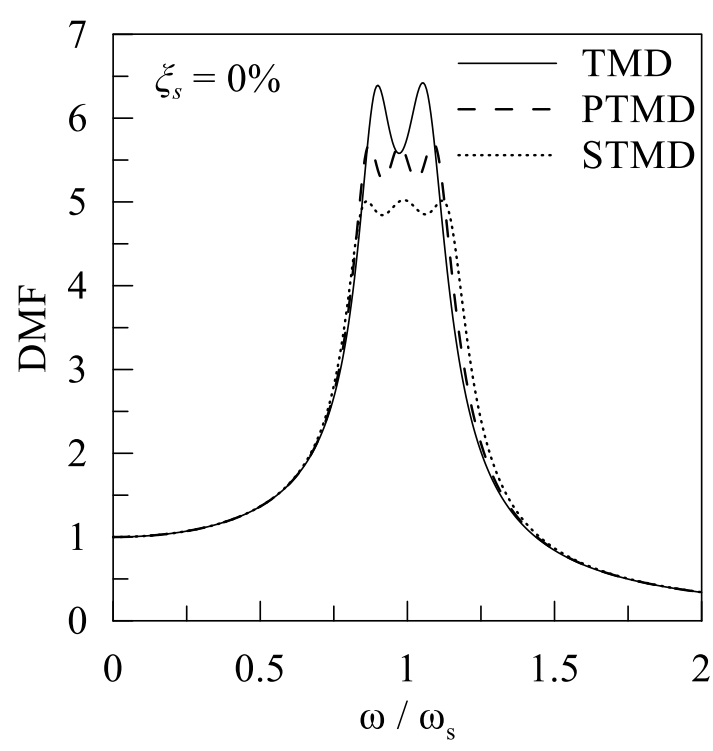

(a)

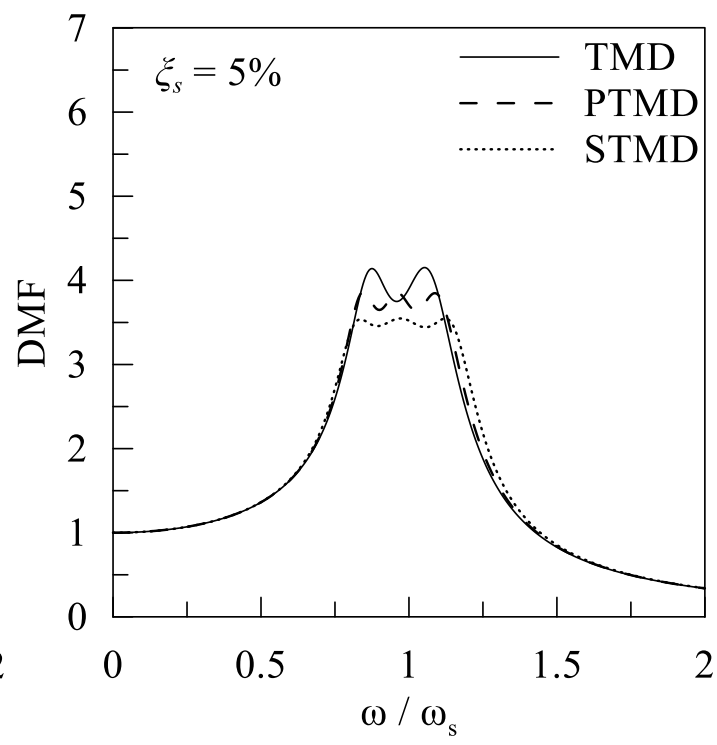

(b)

Figure 9. DMF of the structure equipped with the optimum TMDs for $\mu=0.05$ 


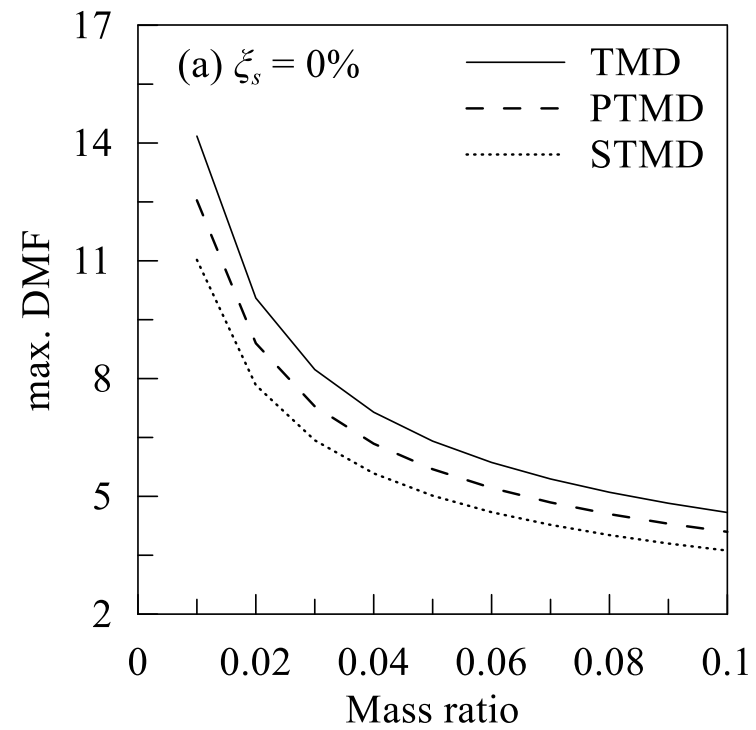

(a)

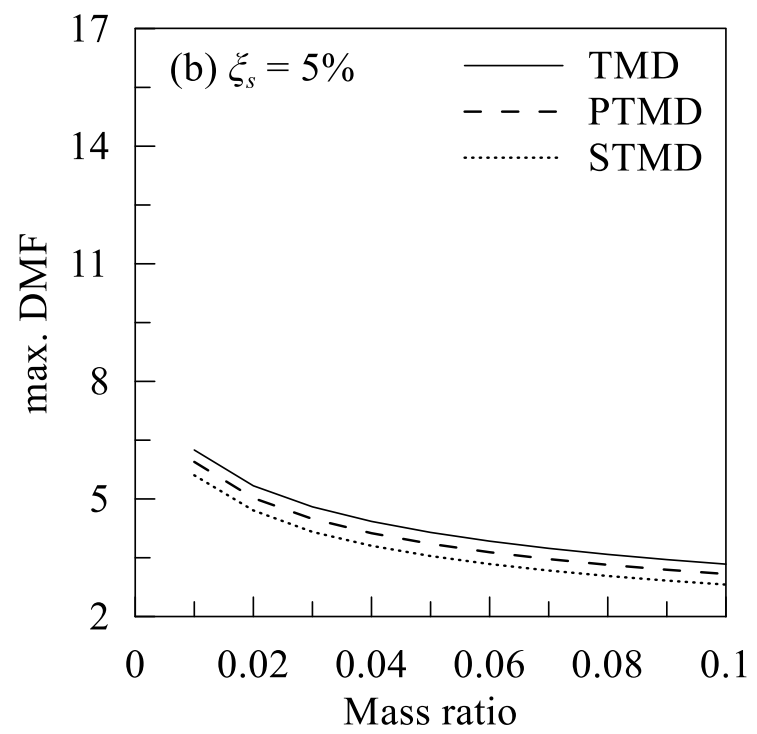

(b)

Figure 10. The maximum DMF versus the mass ratio of TMDs.

Fig. 10 shows the variation of the maximum amplitude concerning the mass ratio for three optimum devices. Fig. 10 indicates that as the mass ratio increases, the values of the maximum amplitude decrease for three optimum TMD systems. Also, it should be noted that the optimum STMD offers a higher effectiveness than the optimum PTMD while the optimum TMD produces the worst control performance as compared with other TMD systems. Fig. 10(a) indicates that the maximum amplitude value of 5 is achieved by optimal designed STMD with $\mu=5.11 \%$ while the same value is achieved by optimally designed TMD and PTMD systems with $\mu=8.48 \%$ and $6.64 \%$, respectively. As compared with STMD system, TMD and PTMD systems must have $65 \%$ and $30 \%$ additional mass ratios, respectively. The same results can also be obtained from Fig. 10(b).

\section{Conclusions}

The effectiveness and optimum parameters of PTMD and STMD for undamped $\left(\xi_{s}=0 \%\right)$ and damped $\left(\xi_{s}=5 \%\right)$ structures are investigated in detail. The optimization of the STMD is obtained by using the SA method. The conclusions can be summarized as follows.

- When the frequency ratio of the first TMD in the STMD and PTMD systems compares with the classical TMD, STMD system has the biggest, while TMD system has a bigger value than PTMD system. For the second TMD unit, PTMD has the biggest value, while TMD has a bigger value than STMD. The tuning frequency ratio decreases as the structural damping ratio increases.

- When the damping ratio of the first TMD in the STMD and PTMD systems compares with the classical TMD, TMD is the biggest, and PTMD is bigger than TMD. For the second TMD unit, STMD is the biggest, and TMD is bigger than PTMD. The tuning frequency ratio increases as the structural damping ratio increases.

- The optimum damping ratio of the first TMD in the STMD is obtained to be zero at all mass ratios. Thus, first TMD unit only consists of mass and stiffness.

- In the STMD system, the second TMD's optimum frequency ratio increases whereas the first TMD's optimum frequency ratio and second TMD's optimum damping ratio decreases with the increase of the mass ratio $\mu$.

- The STMD system has a better effectiveness to the changes in the structural natural frequency in comparison with the other systems.

- To achieve the same control performance with the three different TMD systems, TMD and PTMD must have $65 \%$ and $30 \%$ more mass ratio as compared with the STMD, respectively. 
- The optimum STMD and PTMD with seven absorbers provide approximately the same control performance. Thus, the use of STMD in structural vibration suppression may be more economical than that of multiple parallel TMDs.

\section{Conflict of Interest}

No conflict of interest was declared by the author.

\section{References}

Asami, T., 2017. Optimal Design of Double-Mass Dynamic Vibration Absorbers Arranged in Series or in Parallel. J Vib Acoust, $139(1), 011015$

Asami, T., Mizukawa, Y., Ise, T., 2018. Optimal Design of Double-Mass Dynamic Vibration Absorbers Minimizing the Mobility Transfer Function. J Vib Acoust, 140(6), 061012.

Aydin, E., Ozturk, B., Bogdanovic, A., Farsangi, E.N., 2020. Influence of Soil-Structure Interaction (SSI) on Optimal Design of Passive Damping Devices. (2020). Structures, 28, 847-862.

Bekdaş, G., Nigdeli, S.M., Yang, X.S., 2018. A Novel Bat Algorithm Based Optimum Tuning of Mass Dampers for Improving the Seismic Safety of Structures. Engineering Structures, 159, 89-98.

Bakre, S.V., Jangid, R.S., 2004. Optimum Multiple Tuned Mass Dampers for Base-Excited Damped Main System. Int J Struct Stab Dyn, 4(4), 527-542.

Cetin, H., Aydin, E., Ozturk, B., 2017. Optimal Damper Allocation in Shear Buildings with Tuned Mass Dampers and Viscous Dampers. International Journal of Earthquake and Impact Engineering, 2(2), 89-120.

Cetin, H., Aydin, E., Ozturk, B., 2019. Optimal Design and Distribution of Viscous Dampers for Shear Building Structures under Seismic Excitations. Frontiers in Built Environment, 5, 90.

Den Hartog, J.P., 1956. Mechanical Vibrations. Dover, New York.

Fujino, Y., Abe, M., 1993. Design Formulas for Tuned Mass Dampers based on a Perturbation Technique. Earthquake Engineering and Structural Dynamics, 22, 833-854.

Kim, S.Y., Lee, C.H., 2018. Optimum Design of Linear Multiple Tuned Mass Dampers Subjected to White Noise Base Acceleration Considering Practical Configurations. Eng Struct, 171, 516-528, 2018.

Kirkpatrick, S., Gelatt, C.D., Vecchi, M.P., 1983. Optimization by Simulated Annealing. Science, 220(4598), 671-680.

Leung, A.Y.T., Zhang, H., Cheng, C.C., Lee, Y.Y., 2008. Particle Swarm Optimization of TMD by Non-Stationary Base Excitation During Earthquake. Earthquake Engineering and Structural Dynamics, 37(9), 1223-1246.

Li, C., Zhu, B., 2006. Estimating Double Tuned Mass Dampers for Structures under Ground Acceleration using a Novel Optimum Criterion. J Sound Vib, 298, 280-297.

Li, H.N., Ni, X.L., 2007. Optimization of Non-Uniformly Distributed Multiple Tuned Mass Damper. J Sound Vib, 308, 80-97.

Matta, E., 2013. Effectiveness of Tuned Mass Dampers against Ground Motion Pulses. Journal of Structural Engineering, 1339(2), 188-198.

Mohebbi, M., Rasouli, H., Moradpour, S., 2015. Assessment of the design criteria effect on performance of multiple tuned mass dampers. Adv Struct Eng, 18(8), 1141-1158.

Rana, R., Soong, T.T., 1998. Parametric Study and Simplified Design of Tuned Mass Dampers. Engineering Structures, 20(3), 193-204.

Rao, S.S., 2009. Engineering Optimization: Theory and Practice. Wiley, New Jersey.

Salvi J., Rizzi, E., 2016. Closed-Form Optimum Tuning Formulas for Passive Tuned Mass Dampers under Benchmark Excitations. Smart Structures and Systems, 17(2), 231-256.

Xu K., Igusa, T., 1992. Dynamic Characteristics of Multiple Substructures with Closely Spaced Frequencies. Earth. Eng Struct Dyn, 21(12), 1059-1070.

Zuo, L., 2009. Effective and Robust Vibration Control using Series Multiple Tuned-Mass Dampers. J Vib Acoust, 131, 031003. 